\title{
Diphenyltetrazole Modified Bacterial Cellulose Film: Considerations on Heterogeneous Modification and Bioconjugation
}

\author{
Simone Birkheur ${ }^{a}$,Edson Laureto ${ }^{b}$, Ricardo Vignoto Fernandes ${ }^{b}$, Cesar Tischer ${ }^{c}$, \\ Anna Paola Butera ${ }^{a}$, Renato M. Ribeiro-Viana ${ }^{d *}$ (B) \\ ${ }^{a}$ Universidade Estadual de Londrina (UEL), Departamento de Química, CEP 86051-980, Londrina, PR, Brasil \\ ${ }^{b}$ Universidade Estadual de Londrina (UEL), Departamento de Física, CEP 86051-980, Londrina, PR, Brasil \\ ${ }^{c}$ Universidade Estadual de Londrina (UEL), Departamento de Bioquímica e Biotecnologia, \\ CEP 86051-980, Londrina, PR, Brasil \\ ${ }^{d}$ Universidade Tecnológica Federal do Paraná (UTFPR-Ld), Departamento Acadêmico de Química, \\ CEP 86036-370, Londrina, PR, Brasil
}

Received: May 7, 2020; Revised: June 1, 2020; Accepted: June 17, 2020

\begin{abstract}
Understanding chemical reactions in bacterial cellulose (BC) films is important to control the insertion of biomolecules that can improve their biomedical properties. Diphenyltetrazole molecules are able to react with tiols under UV irradiation and has been useful for immobilize proteins on different materials. In this work, we show the functionalization of a BC film with diphenyltetrazole and subsequent attempts of conjugation of the bovine serum albumin (BSA) to it. Diphenyltetrazole was synthesized in two steps, and functionalization of it with BC was carried out under ultrasound irradiation. Spectroscopic analysis of the film by UV-Vis and FTIR confirmed the success of the reaction. Attempts to conjugate BSA to the modified cellulose film by photoclick reaction failed under these conditions. Although this methodology is important in the conjugation of biomolecules, we understand that its application in cellulosic materials in heterogeneous phase is disadvantaged due to the half-life of the unstable intermediate and the biomolecule's access to it.
\end{abstract}

Keywords: bacterial cellulose, bioconjugation, photoclick.

\section{Introduction}

Protein immobilization, with or without enzymatic activity, to polymeric supports is a widely explored strategy aimed at the preparation of new biomaterials with different biomedical applications ${ }^{1-4}$. Polymeric supports employed in protein immobilization can be of organic or inorganic nature. Among the inorganic matrix, mesoporous silica is one of the most used, and it is useful even in large scale immobilizations ${ }^{5}$. Successful protein coupling has been described for many applications, for instance, to promote human endothelial growth on polyurethane conjugated to RGD sequence $^{6}$, for the construction of enzymatic biosensors ${ }^{7}$ and for industrial use ${ }^{8}$. Synthetic polymers, despite being widely used as the commercial methacrylate epoxy, are not biodegradable ${ }^{9}$. Natural polymers, on the other hand, do show biodegradation and have low contamination risk to the environment. Among these matrices, polysaccharides should be highlighted, and agarose, chitosan, and cellulose are commonly used for many purposes ${ }^{10}$. Bacterial cellulose (BC) is a polysaccharide comprised of repeating units of $\beta$-1,4-D-glucopyranose, and it is produced by some bacteria. It is formed in fermentation medium in high purity and is free from pectin, lignin, and hemicellulose, unlike that of vegetal origin $^{11}$. In addition to its purity, it has a dense hydrogen bond

*e-mail: renatoviana@utfpr.edu.br network, which gives it high crystallinity and mechanical resistance. It also has good water retention capacity and, due to these factors, it is used as a skin substitute, as wound bandages, in recovering blood vessels and cardiac valves, and other applications have been described for different cellulose-based biomaterials ${ }^{12-14}$. To add new features to biomaterials, covalent protein immobilization is an interesting approach because it leads to more controlled and stable materials/enzymes. However, cellulose hydroxyl groups are not able to react directly with functional groups present in proteins (mostly amine, carboxylate, or sulfidryl) and, thus, it is necessary to provide adequate functionalization of this material as a first step ${ }^{10,15,16}$. In this context, click chemistry reactions have been applied to functionalize different types of materials successfully ${ }^{17-19}$. In recent decades, photoclick reactions have been widely studied in the search of combining regioselectivity, the speed of the chemical process, and high yield $^{20,21}$. The diaryltetrazole group was recognized as a versatile functional group for photoclick reactions. The tetrazole ring is stable under normal conditions, but under ultraviolet irradiation it forms an intermediate that is highly reactive in the presence of some nucleophiles ${ }^{22,23}$. For instance, this methodology was used to promote selective coupling of thiols to a polyethyleneglycol diphenyltetrazole-modified polymer $^{20}$. This procedure was proven to be very advantageous due to its occurrence in the absence of catalysts, and the only 
byproduct formed was $\mathrm{N}_{2}(\mathrm{~g})$. Another important feature is that this condition is water compatible, which is desirable for reactions with biomolecules, thus preventing protein denaturation and loss of activity.

Considering the qualities of the reactions using diphenyltetrazole, in this work we have studied this methodology to functionalized bacterial cellulose films with diphenyltetrazoles groups and to couple a protein containing a sulfidryl group to BC films. Although the cellulose film was successfully decorated with these molecules, protein conjugation demonstrated not to be efficient in this heterogeneous medium, therefore proving to be a limitation of this technique.

\section{Experimental Part}

\subsection{Materials}

4-formylbenzoic acid, p-toluenesulfonehydrazide, $N, N$ - Dicyclohexylcarbodiimidep (DCC), $\mathrm{N}, \mathrm{N}$-dimethylaminepyridine (DMAP) and Coomassie brilliant blue (BG-250) dye were purchased from Sigma-Aldrich and were used without purification. Anhydrous solvents were dried over molecular sieves ( $3 \AA$ ) for $48 \mathrm{~h}$. In the reactions induced by UV radiation, a high brightness 309-nm LED was used as the light source. The reactions under ultrasound irradiation were performed in an ultrasound cleaner - model Ultra Sônico - USC - 3300 (220 W, $40 \mathrm{KHz})$.

\subsection{Methods}

\subsubsection{Bacterial cellulose production}

The Acetobacter xylinum ATCC 23769 (Gluconacetobacter xylinus ATCC 23769) bacterial strain was grown in a glucose medium based on the Hestrin-Schramm culture medium ${ }^{24}$. The cellulose was produced as described by Goelzer et al. ${ }^{25}$. The bacterial cellulose pellicle was purified by immersion in an aqueous solution of $0.1 \mathrm{~mol} / \mathrm{L}$ sodium hydroxide for one day. The films were repeatedly washed with deionized water until reaching $\mathrm{pH} 7$.

\subsection{Analytical methods}

\subsubsection{Liquid-state NMR analysis}

${ }^{1} \mathrm{H}$ and ${ }^{13} \mathrm{C}$ spectra were recorded on a Bruker Avance III $400 \mathrm{MHz}$ spectrometer, operating at a frequency of $400.6 \mathrm{MHz}$ for ${ }^{1} \mathrm{H}$ and $100 \mathrm{MHz}$ for ${ }^{13} \mathrm{C}$, using a 5-mm inverse probe, $\mathrm{BBI}$, at $25^{\circ} \mathrm{C}$. Chemical shifts $(\delta)$ for ${ }^{1} \mathrm{H}$ spectra are expressed in ppm and calibrated according to the residual solvent signal ( $\mathrm{CHCl} 3 ; \delta=7.26$ ppm; HOD: $\delta=4,76$ ppm). Chemical shifts $(\delta)$ for the ${ }^{13} \mathrm{C}$ spectrum are expressed in ppm and calibrated according to the solvent signal $\left(\mathrm{CDCl}_{3} ; \delta=77.00 \mathrm{ppm}\right)$.

Fourier transform infrared (FT-IR) spectroscopy analysis

Infrared spectra were recorded on a Shimadzu Fourier transform infrared (FT-IR) PRESTIGE- spectrometer directly from the film in the range of $4000-400 \mathrm{~cm}^{-1}$. Sixteen scans were taken for each sample, with a resolution of $1 \mathrm{~cm}^{-1}$ in the transmission mode.

\section{UV-Vis analysis}

Ultraviolet-visible (UV-Vis) analyses of the membranes were carried out in a Shimadzu UV-2600 spectrophotometer in the $200-800 \mathrm{~nm}$ range while equipped with a film holder (P/N 204-58909) directly in the film.

\subsection{Synthesis}

\subsubsection{Synthesis of 4-((2-tosylhydrazono)methyl)benzoic acid 1}

A mixture containing $100 \mathrm{mg}(0.6 \mathrm{mmol})$ of 4-formylbenzoic acid and $148 \mathrm{mg}(0.796 \mathrm{mmol})$ of p-toluenesulfonehydrazide in $7.5 \mathrm{~mL}$ of ethanol was refluxed for 6 hours. The product was precipitated by adding water, and after filtration $199 \mathrm{mg}$ $(0.626 \mathrm{mmol})$ of a white solid was obtained as the product with $94 \%$ yield.

\subsubsection{Synthesis of 4-(2-phenyl-2H-tetrazol-5-yl) benzoic acid $\mathbf{2}$}

A solution containing $172 \mu \mathrm{L}$ of aniline $(1.89 \mathrm{mmol})$, $1.5 \mathrm{~mL}$ of ethanol, $1.5 \mathrm{~mL}$ of water, and $3.0 \mathrm{~mL}$ of concentrated hydrochloride acid $(37 \% \mathrm{w} / \mathrm{v})$ was stirred in an ice bath for 20 minutes. After that, $0.8 \mathrm{~mL}$ of a $\mathrm{NaNO}_{2(\mathrm{aq})}$ solution $(2.36 \mathrm{~mol} / \mathrm{L})$ was added dropwise to the first solution. The resulting solution was added slowly to another solution containing $400 \mathrm{mg}$ ( $1.26 \mathrm{mmol})$ of 2 in $6.7 \mathrm{~mL}$ of pyridine in an ice bath. The solution was stirred for 4 hours at $0^{\circ} \mathrm{C}$. After 20 hours, $20 \mathrm{~mL}$ of $\mathrm{CH}_{2} \mathrm{Cl}_{2}$ was added to the final solution and the mixture was washed with $0.1 \mathrm{~mol} / \mathrm{L} \mathrm{HCl}$ (7 times, $40-\mathrm{mL}$ each) and then with brine $(\mathrm{NaCl}$ saturated solution, 3 times, 20-mL each). The organic phase was dried over $\mathrm{Na}_{2} \mathrm{SO}_{4}$ and the solvent was evaporated under reduced pressure. The syrup obtained was dissolved in warm ethanol and precipitated with the addition of water. A red solid was obtained ( $35 \mathrm{mg}, 0.131 \mathrm{mmol}$ ) with $41 \%$ yield.

Esterification of bacterial cellulose with 4-(2-phenyl-2H-tetrazol-5-yl)benzoic acid (BC-Tz)

Before the reactions, the cellulose membranes were prepared by solvent exchange in order to eliminate the excess water, which represents a problem for reactions with activated acyl groups. First, they were immersed in methanol and soaked for five minutes. The solvent was discarded, and the same procedure was repeated two more times. Then, the membranes were immersed in dichloromethane and gently soaked for five minutes. The solvent was discarded, and the same procedure was repeated two additional times.

A BC film (10 mg, $0.061 \mathrm{mmol}$ of anhydroglucose unit - AGU), previously solvent exchanged, was added to a neutral glass test tube with Screw Cap $(25 \mathrm{~mL}-18 \times 150 \mathrm{~mm})$, and then $1.5 \mathrm{~mL}$ of anhydrous $\mathrm{CH}_{2} \mathrm{Cl}_{2}, 32 \mathrm{~mL}$ of 4-(2-phenyl2H-tetrazol-5-yl)benzoic acid $2(0.123 \mathrm{mmol}), 31 \mathrm{mg}$ of DCC $(0.148 \mathrm{mmol})$, and $15 \mathrm{mg}$ of DMAP $(0.123 \mathrm{mmol})$ were added to the same tube and the tube was sealed. The reaction was submitted to ultrasonic irradiation for 6 hours. After that time, the film was washed with water and ethanol and finally dried at room temperature. 


\subsection{Quantification of esterification degree onto BC films}

In a $50 \mathrm{~mL}$ volumetric flask, a $200 \mu \mathrm{mol} / \mathrm{L}$ solution of diphenyltetrazol was prepared by dissolving $2.66 \mathrm{mg}$ in $\mathrm{NaOH}$ (aq) solution $(0.1 \mathrm{~mol} / \mathrm{L})$. From this solution, others were prepared $(40,35,30,25,20,15$, and $10 \mu \mathrm{mol} / \mathrm{L})$ using the $\mathrm{NaOH}(\mathrm{aq})$ solution $(0.1 \mathrm{~mol} / \mathrm{L})$ as the diluent. All solutions were submitted to analysis using a UV-Vis spectrophotometer and were measured at $278 \mathrm{~nm}$. The standard curve was built using the absorbance values for each concentration at $278 \mathrm{~nm}$ versus the concentration of the standard solution. These data were used to perform the linear regression.

A film of modified cellulose $(3.7 \mathrm{mg} ; 22 \mu \mathrm{mol}$ of AGU) was treated with $1 \mathrm{~mL}$ of $\mathrm{NaOH}(\mathrm{aq})(0.1 \mathrm{~mol} / \mathrm{L})$ and sonicated for 6 hours. Then, the film was washed with $1 \mathrm{~mL}$ of $\mathrm{NaOH}(\mathrm{aq})(0.1 \mathrm{~mol} / \mathrm{L})$ and combined with the supernatant (resulting in $2 \mathrm{~mL}$; solution A). Next, $0.5 \mathrm{~mL}$ of solution A was taken and diluted to $5 \mathrm{~mL}$ using $\mathrm{NaOH}$ (aq) $(0.1 \mathrm{~mol} / \mathrm{L})$ (solution B). This last procedure was repeated 2 more times. Solution B was measured at $278 \mathrm{~nm}$, and the tetrazole concentration was found using the standard curve.

\subsection{Conjugation}

A modified film of BC (3.4 mg, $21 \mu \mathrm{mol}$ AGU) was immersed in $2 \mathrm{~mL}$ of phosphate buffer saline (PBS) $\left(0.137 \mathrm{M} \mathrm{NaCl}, 0.01 \mathrm{M} \mathrm{Na}_{2} \mathrm{HPO}_{4}\right.$ and $0.0018 \mathrm{M} \mathrm{KH}_{2} \mathrm{PO}_{4}$ $\mathrm{pH} 7.4$ ) in a beaker. Then, $300 \mathrm{uL}$ of a PBS solution containing $2 \mathrm{mg}$ of BSA was added. This mixture stood under direct UV (309 nm) irradiation for 7 hours. Finally, the film was washed with distilled water and dried at room temperature.

\subsubsection{Protein quantification by Bradford Method ${ }^{26}$}

CB-Tz and CB-Tz-BSA films were placed in separate test tubes, to which $1 \mathrm{~mL}$ of 0.1 mol.L-1 NaOH solution ( $\mathrm{pH}$ 12.0) was added, and then remained in an ultrasonic bath for 6 hours. Subsequently, the supernatant from each test tube was collected together with an additional $1.0 \mathrm{~mL}$ of alkaline solution used to wash the resulting cellulose films, making a final volume of $2.0 \mathrm{~mL}$ (Tz and Tz-BSA solutions). In a UV-vis spectrometer, at $595 \mathrm{~nm}$, absorbance values were obtained for solutions prepared from $100 \mu \mathrm{L}$ of Tz solution and Tz-BSA solution and $1 \mathrm{~mL}$ of Coomassie brilliant blue (BG-250) dye (100 mg of G-250 dissolved in $50 \mathrm{ml}$ of $100 \%$ ethanol; $100 \mathrm{~mL}$ of $85 \%$ phosphoric acid, complete the volume to $1 \mathrm{~L}$ with miliQ water).

\section{Results and Discussion}

The strategy developed in this work for studying the immobilization of proteins onto film surfaces takes into account the use of conditions that may occur in the presence of water. This is desirable so as to avoid protein denaturation, as well as for the reaction to be fast and selective to certain functional groups. Based on that, diphenyltetrazol $\mathbf{2}$ was coupled to the cellulose surface, considering that this molecule is able to promote photoclick conjugations with thiols ${ }^{20}$. BSA was chosen as the protein model, since it is known that this protein has a sulfidryl group facing the external face (Figure 1).

Initially, diphenytetrazol derivative $\mathbf{2}$ was synthesized in two steps, as described by Hiltebrandt et al. ${ }^{27}$. Tosylhydrazone 1 was obtained by the condensation of 4-fomylbenzoic acid and p-toluenesulfonehydrazine with $94 \%$ yield. The success of the reaction was confirmed by ${ }^{1} \mathrm{H}$ NMR, where a methyl signal at $2.6 \mathrm{ppm}$ and aromatic and hydrazine hydrogen signals between 7.66 and 7.41 could be seen. Other signals and ${ }^{1} \mathrm{H}$ NMR spectrum are presented in supplementary material (Figure S1, supplementary material).

Reaction of tosylhydrazone 1 with the diazone salt of aniline leads to formation of diphenyltetrazol 2 as a red solid with $42 \%$ yield. This compound was characterized by ${ }^{1} \mathrm{H}$ NMR, showing only aromatic hydrogens between 8.30 and 7.64 ppm. ${ }^{1} \mathrm{H}$ NMR spectrum and spectroscopic description of molecule are presented in supplementary material (Figure S2, supplementary material).

The next step was to couple the diphenyltetrazol to the cellulose surface using an esterification reaction in anhydrous solvent. A reaction condition study was conduct in order to find out the best procedure to esterify the

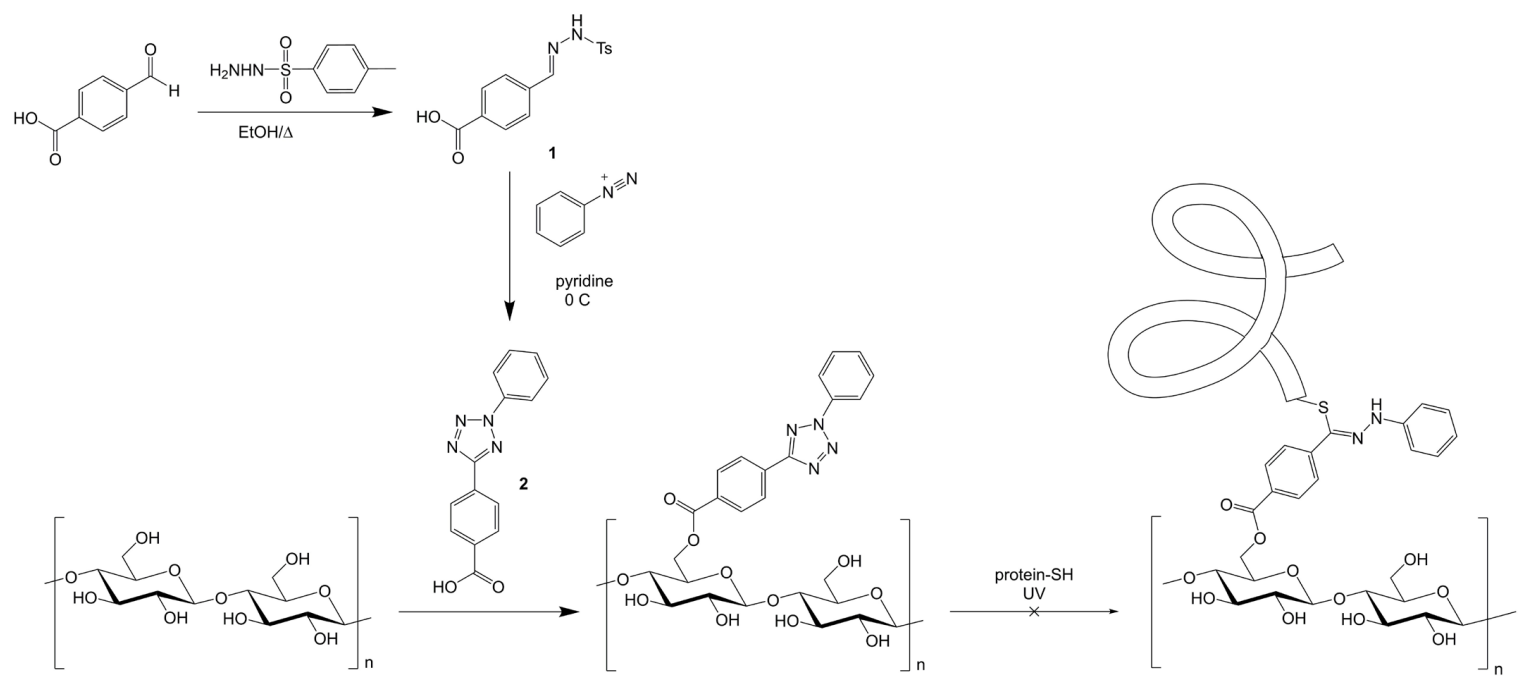

Figure 1. Strategy for functionalization of bacterial cellulose (BC) films with diphenyltetrazol and proteins. 
diphenyltetrazole to the cellulose hydroxyls, including varying the solvent, temperature, and exposure to ultrasound radiation (Table 1). The success of the reaction was determined by the evidence of typical bands present in the infrared and ultraviolet spectra.

The conditions where dichloromethane was employed as the solvent were successful (conditions 3 and 4), and the sample submitted to ultrasound irradiation showed the best esterification results, according to IR and UV-Vis spectra. Ultrasound irradiation is a good technique when working with heterogeneous systems due to the increasing shocks of solvent/reagent onto the film surface ${ }^{28}$. In our group, we have already used this methodology to perform reactions at the surface of BC films, with success ${ }^{29}$ using an ultrasound probe. Now we have extended this approach to typical ultrasound cleaners commonly used in laboratories.

In the IR spectra (Figure 2), a band at $1715 \mathrm{~cm}^{-1}$ is observed for conditions 3 and 4 . This band is typical of aromatic ester $\mathrm{C}=\mathrm{O}$ stretching, thus confirming the coupling of tetrazole to the cellulose hydroxyls. In condition 3, there is only a small shoulder related to the carbonyl band, indicating less coupling, while in condition 4, there is a more intense band, confirming the beneficial effect of the use of ultrasound irradiation.

Data obtained from UV-Vis spectra are consonant with infrared (IR) spectroscopy results. BC does not possess any important chromophore that absorbs in the ultraviolet-visible range. Thus, this spectroscopy is quite useful for evaluating successful reaction when chromophores groups are added. In the UV-Vis spectrum (Figure 3 ), there is a strong band at $\lambda \max =280 \mathrm{~nm}$ for condition 4 and a smaller band at the

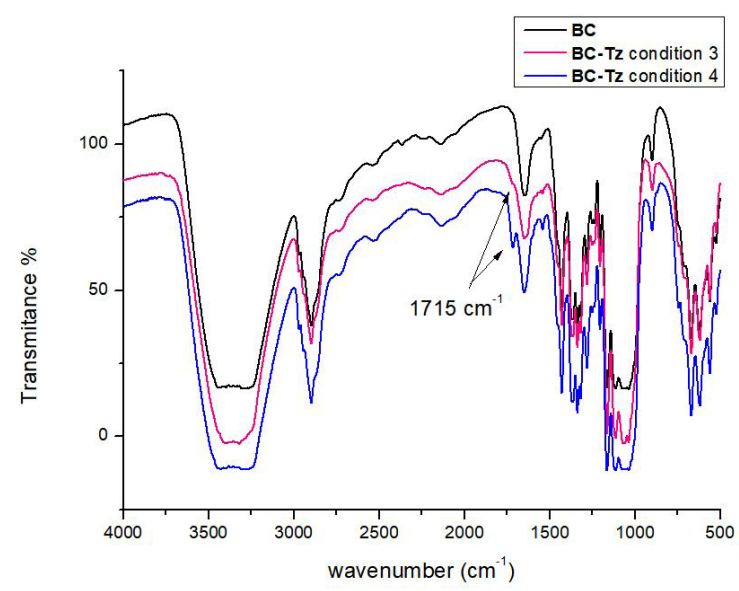

Figure 2. Infrared spectra of $\mathrm{BC}$ and films modified with diphenyltetrazol (BC-Tz). same wavelength for condition 3 , confirming the introduction of tetrazole onto the cellulose surface.

To further characterize the material, quantification of cellulose esterification by tetrazole groups was performed using UV-Vis spectroscopy, determining the molar concentration of diphenyltetrazole in an alkaline solution obtained after cellulose ester group hydrolysis. Basically, functionalized cellulose films were submitted to alkali hydrolysis conditions ( $\mathrm{NaOH}$ solution, $1 \mathrm{~mol} / \mathrm{L}$, for 1 hour) in a known volume, and a sample of this solution was withdrawn for quantification by UV-Vis spectroscopy. The success of the diphenyltetrazole hydrolysis was confirmed by IR and UV-Vis spectra of the film (Figure 4), where there was the disappearance of the respective band of such molecule.

A proper calibration curve was constructed using alkaline solutions of diphenyltetrazole (Figure S3, supplementary material), and the sample obtained from the hydrolysis solution was measured with UV-Vis spectroscopy. The amount of the compound released from cellulose films was calculated using the standard curve previously constructed. A degree of substitution (DS) of 0.02 was found for this procedure. This data explains the lower intensity carbonyl found in the IR spectrum (Figure 2), when compared to others reactions, for instance, introduction of succinyl group to cellulose, which showed a higher DS and intensity band ${ }^{30}$. As BC is a high crystalline biopolymer, in which many of the hydroxyls are not available to react, and the reaction takes place at the heterogeneous phase, it is not strange that its yield is not as high as when the system is homogeneous ${ }^{16}$. Besides, the carboxylic acid used is appended in an aromatic group, which deactivates it toward reactions and, thus,

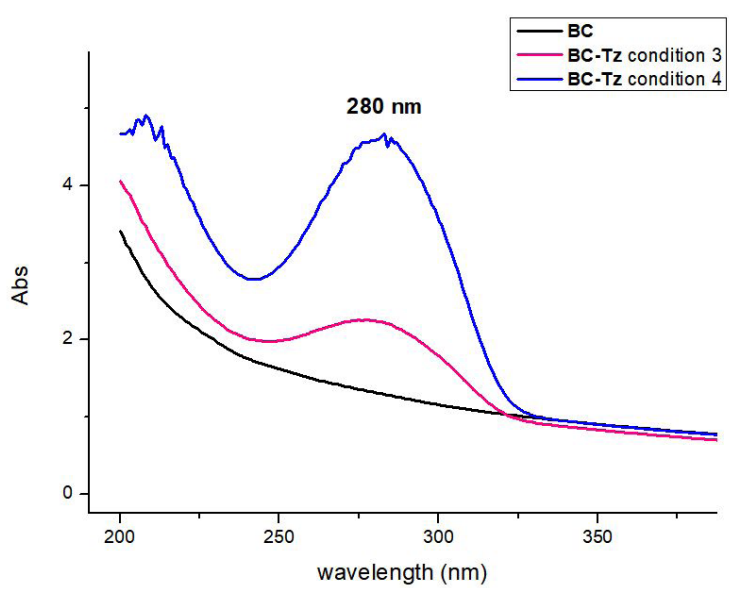

Figure 3. Ultraviolet-visible (UV-Vis) spectra of $\mathrm{BC}$ and films modified with diphenyltetrazol (BC-Tz).

Table 1. Effect of solvent, temperature, time, and exposure to ultrasonic irradiation for the esterification of BC by reaction with 2 and DCC/DMAP.

\begin{tabular}{|c|c|c|c|c|c|}
\hline Condition & Solvent & Temperature & Time & $\begin{array}{l}\text { Ultrasound } \\
\text { irradiation }\end{array}$ & Result \\
\hline 1 & DMF & $45^{\circ} \mathrm{C}$ & 22 hours & no & negative \\
\hline 2 & DMF & $25^{\circ} \mathrm{C}$ & 6 hours & yes & negative \\
\hline 3 & $\mathrm{CH}_{2} \mathrm{Cl}_{2}$ & $25^{\circ} \mathrm{C}$ & 20 hours & no & positive \\
\hline 4 & $\mathrm{CH}_{2} \mathrm{Cl}_{2}$ & $25^{\circ} \mathrm{C}$ & 6 hours & yes & positive \\
\hline
\end{tabular}



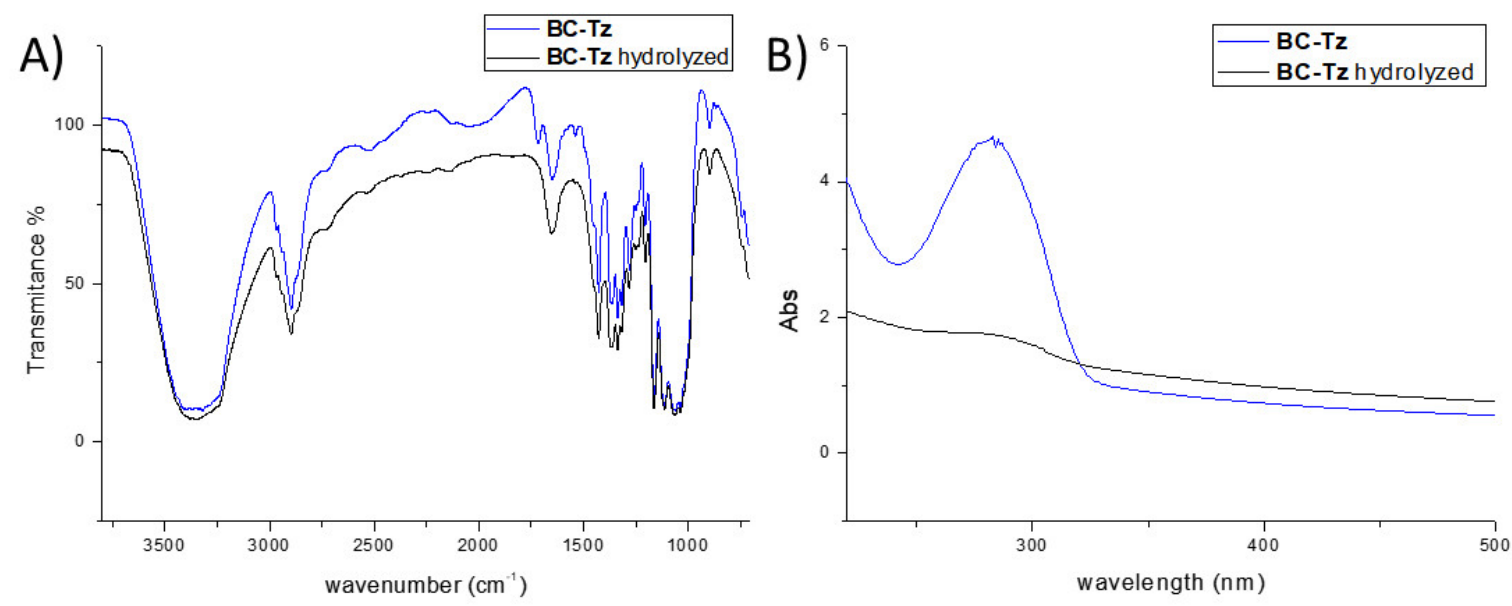

Figure 4. Infrared (A) and Ultraviolet-visible (B) Spectra of bacterial cellulose modified with tetrazole group, before and after hydrolysis reaction.

makes the modification process even more difficult and explains the low DS found. In fact, the best way to obtain higher DS yields using cellulose would be solubilizing the polymer in solvent systems like Dimethylacetamide/LiCl or Dimethyl sulfoxide/tetrabutylammonium fluoride, which are much frequently used for this purpose in the literature. However, this kind of approach completely modify the morphological structure of cellulose and thus losing all the unique characteristics of films produced by bacteria ${ }^{16}$. The strategy followed in our group is to find conditions to perform heterogeneous reactions using $\mathrm{BC}$ to add new features to it without disrupting its native characteristics. Besides, it should be noted that to conjugate the diphenyltetrazole to the hydroxyls of cellulose, this specific carboxylic acid used has a benzylic carbonyl, which is by definition less reactive than an aliphatic, and, thus, makes the modification process even more difficult and explains the low DS found.

Once the cellulose film was functionalized with the tetrozole group, the next step was to test the immobilization of a protein via the photoclick reaction. Before starting with protein coupling to cellulose modified film, a model reaction was performed to find the best condition, using a diphenyltetrazole ester and mercaptoethanol under different ultraviolet sources and solvents. For this, $O$-methyl diphenyltetrazole ester was prepared (Figure S4, supplementary material) and reacted in the presence of the thiol using a LED (309 nm) and xenon lamp (312 nm), and ethanol or ethyl acetate as solvent. In this study, we found that the best results occurred when ethyl acetate was used as a solvent. Regarding the UV light, reaction conducted with xenon lamp didn't consume the starting material (diphenyltetrazole methyl ester). In the other hand, photocoupling under LED irradiation furnished the product of coupling, but with low to medium yield (42\%) even after prolonged reaction times (Figure S5, supplementary material). With this condition in hand, the next step was to perform an assay to conjugate a protein to modified bacterial cellulose film.

We chose BSA as a model protein due to the presence of a free sulfhydryl group pointed towards the outside of its structure $^{31}$, which can react and is essential for the proposed photoclick reaction. Immobilization experiments were conducted in PBS buffer ( $\mathrm{pH}$ 7.4) and at room temperature. Two reaction flasks were used in parallel, both containing modified cellulose films and BSA, but just one was irradiated at $309 \mathrm{~nm}$. The non-irradiated reaction was used as a control experiment. After 7 hours of reaction, both films were washed and analyzed by infrared and UV-Vis spectroscopy. Analysis of both spectra showed signals with little differences in the carbonyl band region. In the IR spectra (Figure 5), there is a small increase in the band at $1650 \mathrm{~cm}^{-1}$, typical of an amide carbonyl stretch, which is expected in the protein presence when compared to the control experiment, although adsorbed water in these films can also explain the differences in the band height, since water possess an angular bending absorption in this region as well.

In this case, Uv-Vis analysis can be quite valuable in distinguishing the presence of proteins, since the pattern of absorption of modified films are different. The UV-Vis spectra showed a large difference between the two films (Figure 6).

The film that was irradiated by UV light showed a strong decrease at $280 \mathrm{~nm}$ due to the tetrazol chromophore and the appearance of a band at $365 \mathrm{~nm}$, which is absent in the spectrum of the film from the control reaction. Besides, the absorption pattern of the film used in the absence of UV light remained the same. It is important to show that a very similar UV-Vis pattern was found when this photoclick reaction was used to couple diphenyltetrazole and the molecule-containing thiol group $^{20}$. However, the distinction between success and failure in coupling a protein structure in the presence of other aromatic groups, such as diphenyltetrazole appended onto cellulose, is reasonably reckless by UV-vis spectroscopy. Therefore, two more experiments were performed to clarify this matter: repeating the photoreaction with similar conditions, but in absence of BSA; and submitting the resulting solution of BC-TZA-BSA hydrolysis to the Bradford method, in order to identify and quantify protein.

Regarding the reaction in the absence of BSA protein, after the same reaction conditions, the film was subjected to ultraviolet analysis, which resulted in a spectrum identical to the pattern found when the coupling took place in the 


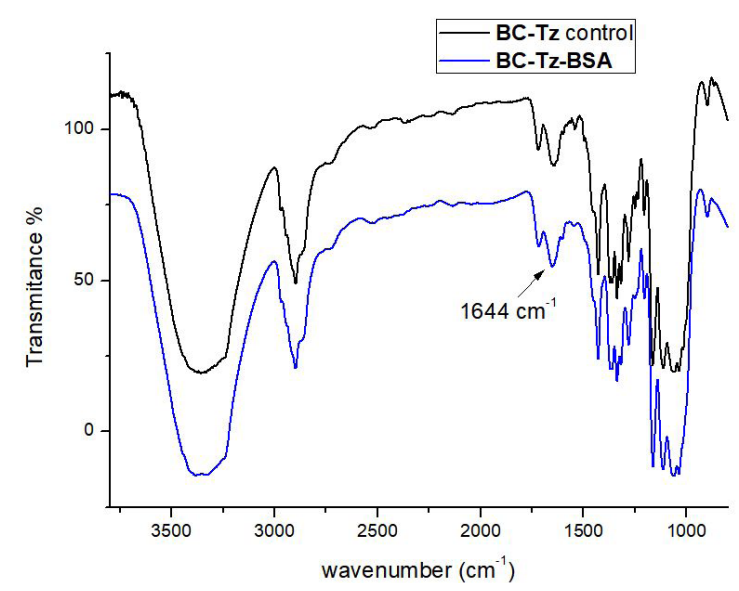

Figure 5. IR spectra of films irradiated under UV light (BC-Tz-BSA) and the control (BC-Tz control).

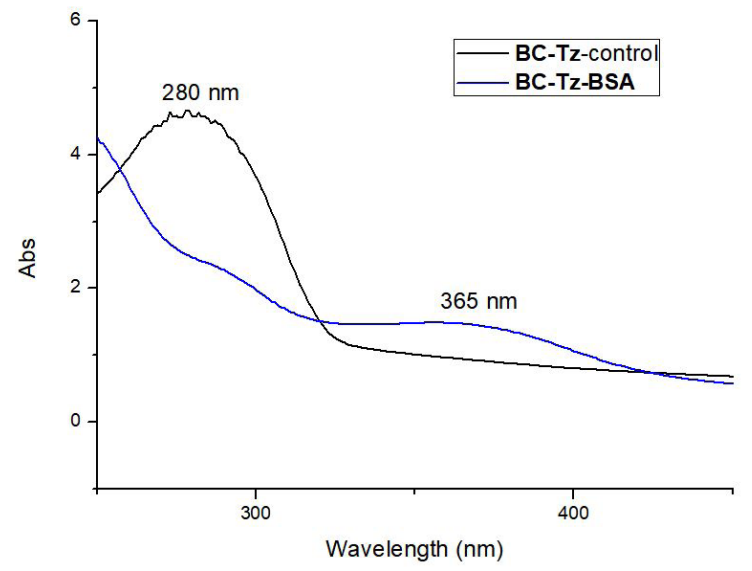

Figure 6. UV-Vis spectra of films irradiated under UV light (BC-Tz-BSA) and the control (BC-Tz control).

presence of this protein (Figure S6, supplementary material). This fact indicates that BSA was not conjugated to cellulose, and also that the diphenyltetrazole is converted to something else after the ultraviolet irradiation.

Considering the protein quantification by Bradford method, after performing an alkaline hydrolysis of the CB-Tz and CB-Tz-BSA films, the resulting solutions were subjected to the BG-250 dye and analyzed in UV-vis spectrophotometer $(595 \mathrm{~nm})$. As the diphenyltetrazole group itself can interact with the dye used in the assay, both experiments values were identified and compared, and showed very low absorbance and similar values $(0,014$ and 0,0159 absorbance units for CB-Tz and CB-Tz-BSA films, respectively). These results also point to a lack of success in the coupling reaction.

Considering all these experiments, it can be understood that the protein coupling to bacterial cellulose did not occur. Apparently, the diphenyltetrazole group undergoes ring opening in the presence of ultraviolet radiation, but does not suffer a nucleophilic attack from the sulfhydryl group of the BSA. The ultraviolet spectrum of the film from the reaction in the absence of protein is an indication that the tetrazole ring converts to another substance and in this case, the same substance is formed in the presence of BSA. In a complementary way, through the analysis using the Bradford method, it is possible to identify that no protein conjugated to the film was identified.

Although this methodology is described in the literature as useful in the coupling of biomolecules to polymers, we have to consider that the model macromolecules described are of PEG type, which are soluble in solvents. This implies that these reactions occur more easily in comparison to the heterogeneous conditions described in this work. One of the reasons for working with heterogeneous reactions in cellulosic materials is to keep the bulk of the material as intact as possible and to preferentially modify the outer face, which, in fact, is in contact with the biophase. However, we know that these reactions are disadvantaged considering the kinetics parameters because they occur in a heterogeneous phase. We understand that when opening the tetrazole ring in the presence of light, the half-life of this reactive intermediate is short to have effective shock with the protein present in the other phase. In addition, considering biomolecules, as proteins, they have high molecular mass and, in this case, only one thiol group per structure, which would also make it difficult to reach the reactive center on the surface of the film. Other experiences of the group with protein and small molecules conjugation to the surface of cellulosic films via formation of amide bond have been successfully reported $^{29,30}$. Considering that the intermediaries in question are less reactive and more stable, they manage to be in the reactive form until the nucleophile attack occurs to them. This leads us to believe that for reactions in heterogeneous phase, at least in cellulosic materials, where the degree of substitution in the polymer by diphenyltetrazole is low (as already explained due to the reaction conditions and low reactivity of aromatic carbonyl), it is very inefficient.

\section{Conclusion}

A cellulose film was functionalized with diphenyltetrazole and then characterized. Reaction conditions were tested and it was identified that using an irradiation by ultrasound source it is possible to modify bacterial cellulose films even with less reactive carbonyls. The coupling reaction using photocatalysis was investigated for more than one type of ultraviolet source and different solvents. However, it was observed that under the conditions used, the coupling reaction does not occur. It is understood that the fast evolution of the intermediate reaction is not suitable for chemical modifications in the heterogeneous phase and tends to decompose before reacting with the biomolecule. Although the reaction has potential for application in various materials, under these specific experimental conditions described, it fails, which indicates that for heterogeneous photoreaction with insoluble materials with low diphenyltetrazole content, like bacterial cellulose films using the described functionalization reaction, it may not be a good methodology for protein conjugation.

\section{Acknowledgements}

The authors would like to thank the Spectroscopy Laboratory at the Universidade Estadual de Londrina (SPEC-UEL-CT INFRA 2009-01.10.0534.01) and to the Multiuser Laboratory 
of Federal University of Technology - Paraná - campus Londrina - for the performed analyses. The authors would also like to acknowledge financial support from CNPq-National Counsel of Technological and Scientific Development (447861/2014-0, and 423643/2018-5).

\section{References}

1. Ito Y. Covalently immobilized biosignal molecule materials for tissue engineering. Soft Matter. 2008;4(1):46-56.

2. Jaganathan H, Mitra S, Srinivasan S, Dave B, Godin B. Design and in vitro evaluation of layer by layer siRNA nanovectors targeting breast tumor initiating cells. PLoS One. 2014;9(4):1-8.

3. Ren X, Ott HC. On the road to bioartificial organs. Pflugers Arch. 2014;466(10):1847-57.

4. Ye X, Wang H, Zhou J, Li H, Liu J, Wang Z, et al. The effect of heparin-VEGF multilayer on the biocompatibility of decellularized aortic valve with platelet and endothelial progenitor cells. PLoS One. 2013;8(1):1-10.

5. Jesionowski T, Zdarta J, Krajewska B. Enzyme immobilization by adsorption: a review. Adsorption. 2014;20(5-6):801-21.

6. Wang D-A, Ji J, Sun Y-H, Shen J-C, Feng L-X, Elisseeff JH. In situ immobilization of proteins and RGD peptide on polyurethane surfaces via poly(ethylene oxide) coupling polymers for human endothelial cell growth. Biomacromolecules. 2002;3(6):128695 .

7. Sassolas A, Blum LJ, Leca-Bouvier BD. Immobilization strategies to develop enzymatic biosensors. Biotechnol Adv. 2012;30(3):489-511.

8. Singh RK, Tiwari MK, Singh R, Lee J. From protein engineering to immobilization : promising strategies for the upgrade of industrial enzymes. Int J Mol Sci. 2013;14:1232-77.

9. Erhardt FA, Jördening HJ. Immobilization of dextranase from Chaetomium erraticum. J Biotechnol. 2007;131(4):440-7.

10. Liu Y, Chen JY. Enzyme immobilization on cellulose matrixes. J Bioact Compat Polym. 2016;31(6):553-67.

11. Lin SP, Loira Calvar I, Catchmark JM, Liu JR, Demirci A, Cheng KC. Biosynthesis, production and applications of bacterial cellulose. Cellulose. 2013;20(5):2191-219.

12. Barud HDS, De Araújo Júnior AM, Saska S, Mestieri LB, Campos JADB, De Freitas RM, et al. Antimicrobial Brazilian propolis (EPP-AF) containing biocellulose membranes as promising biomaterial for skin wound healing. Evid Based Complement Alternat Med. 2013;2013:1-10.

13. Fu L, Zhang J, Yang G. Present status and applications of bacterial cellulose-based materials for skin tissue repair. Carbohydr Polym. 2013;92(2):1432-42.

14. Saska S, Barud HS, Gaspar AMM, Marchetto R, Ribeiro SJL, Messaddeq Y. Bacterial cellulose-hydroxyapatite nanocomposites for bone regeneration. Int J Biomater. 2011;2011:1-8.

15. Tran DN, Balkus KJ. Perspective of recent progress in immobilization of enzymes. ACS Catal. 2011;1(8):956-68.

16. Faria-Tischer PCS, Ribeiro-Viana RM, Tischer CA. Bio-based nanocomposites: Strategies for cellulose functionalization and tissue affinity studies. In: Grumezescu V, Grumezescu AM, editors. Materials for biomedical engineering. Amsterdam: Elsevier; 2019. Chapter 7; p. 205-44.

17. Zou Y, Zhang L, Yang L, Zhu F, Ding M, Lin F, et al. "Click" chemistry in polymeric scaffolds: bioactive materials for tissue engineering. J Control Release. 2018;273:160-79.

18. Li Y, Dong X-H, Zou Y, Wang Z, Yue K, Huang M, et al. Polyhedral oligomeric silsesquioxane meets "click" chemistry: rational design and facile preparation of functional hybrid materials. Polymer. 2017;125:303-29.

19. Chen J, Wang J, Li K, Wang Y, Gruebele M, Ferguson AL, et al. Polymeric "Clickase" accelerates the copper click reaction of small molecules, proteins, and cells. J Am Chem Soc. 2019;141(24):9693-700.

20. Feng W, Li L, Yang C, Welle A, Trapp O, Levkin PA. UVinduced tetrazole-thiol reaction for polymer conjugation and surface functionalization. Angew Chem. 2015;54(30):8732-5.

21. Hein CD, Liu X-M, Wang D. Click chemistry, a powerful tool for pharmaceutical sciences. Pharm Res. 2008;25(10):2216-30.

22. Lim RKV, Lin Q. Photoinducible bioorthogonal chemistry: a spatiotemporally controllable tool to visualize and perturb proteins in live cells. Acc Chem Res. 2011;44(9):828-30.

23. Vonhören B, Roling O, Buten C, Körsgen M, Arlinghaus HF, Ravoo BJ. Photochemical microcontact printing by tetrazole chemistry. Langmuir. 2016;32(9):2277-82.

24. Hestrin S, Schramm M. Synthesis of cellulose by Acetobacter xylinum. II. Preparation of freeze-dried cells capable of polymerizing glucose to cellulose. Biochem J. 1954;58(2):34552.

25. Goelzer FDE, Faria-Tischer PCS, Vitorino JC, Sierakowski MR, Tischer CA. Production and characterization of nanospheres of bacterial cellulose from Acetobacter xylinum from processed rice bark. Mater Sci Eng C. 2009;29(2):546-51.

26. Bradford MM. A rapid and sensitive method for the quantitation microgram quantities of protein utilizing the principle of protein-dye binding. Anal Biochem. 1976;254(1-2):248-54.

27. Hiltebrandt K, Pauloehrl T, Blinco JP, Linkert K, Börner HG, Barner-Kowollik C. $\lambda$-Orthogonal pericyclic macromolecular photoligation. Angew Chem Int Ed. 2015;54(9):2838-43.

28. Mason TJ. Ultrasound in synthetic organic chemistry. Chem Soc Rev. 1997;26(6):443-51.

29. Birkheur S, Faria-Tischer PCS, Tischer CA, Pimentel EF, Fronza $\mathrm{M}$, Endringer DC, et al. Enhancement of fibroblast growing on the mannosylated surface of cellulose membranes. Mater Sci Eng C. 2017;77:672-9.

30. Ribeiro-Viana RM, Faria-Tischer PCS, Tischer CA. Preparation of succinylated cellulose membranes for functionalization purposes. Carbohydr Polym. 2016;148:21-8.

31. Demian WLL, Kottari N, Shiao TC, Randell E, Roy R, Banoub JH. Direct targeted glycation of the free sulfhydryl group of cysteine residue (Cys-34) of BSA. Mapping of the glycation sites of the anti-tumor Thomsen-Friedenreich neoglycoconjugate vaccine prepared by Michael addition reaction. J Mass Spectrom. 2014;49(12):1223-33. 


\section{Supplementary material}

The following online material is available for this article:

Figure S1: Spectroscopic data of 4-((2-tosylhydrazono)methyl)benzoic acid 1.

Figure S2: Spectroscopic data of 4-(2-phenyl-2H-tetrazol-5-yl)benzoic acid 2.

Figure S3 - Analytical curve of diphenyltetrazol 2 solution.

Figure S4 - 1H NMR (400 MHz, CDCl3) spectrum of O-metil 4-(2-phenyl-2H-tetrazole-5-yl)benzoate.

Figure S5-1H NMR (400 MHz, CDCl3) spectrum of coupling product of diphenyltetrazole and 2-mercaptoethanol. Figure S6 - Ultraviolet visible spectra of BC-Tz-BSA and BC-UV (no BSA added).

Table S1 - Absorbances found for the solution containing the diphenyltetrazol 2 (Solution B) after alkaline hydrolysis of BC-Tz.

Tahle S2 - Absorbance values at $278 \mathrm{~nm}$ of diluted solutions of the diphenyltetrazol derivative 2 employed in the construction of the analytical curve. 